\title{
THE DEVELOPMENT OF A NEW OPTICAL METHOD TO MEASURE THE DELAY TIME OF SPARK IGNITION
}

\author{
MARIA MITU ${ }^{\mathrm{a}, \mathrm{b}}$, DOMNINA RAZUS ${ }^{\mathrm{a}}$, DUMITRU OANCEA ${ }^{\mathrm{b},{ }^{*}}$
}

\begin{abstract}
The development of a new optical method to measure the delay time following the spark ignition in gaseous explosive mixtures, based on the measurement of the emitted radiation intensity detected with a photo diode active in visible and near infrared range is presented. Several $\mathrm{CH}_{4}$-air-inert mixtures were used to test the validity of the method. Our results are comparable with the available literature data. The influence of the different operational factors was investigated to establish the range of the optimum conditions.
\end{abstract}

Keywords: spark ignition, ignition delay, emitted radiation intensity, $\mathrm{CH}_{4}$-airinert mixtures

\section{INTRODUCTION}

The homogeneous combustion reactions in gas phase are complex reactions involving hundreds of molecular species and coupled elementary reactions. They are generally exothermic reactions and many imply also the participation of chain-branching mechanism. A simplified picture of temperature increase in time was suggestively illustrated in literature [1]. Using a (log T) against time diagram for thermal and chain branching explosions, a straight-line passing through origin or a straight-line intersecting $X$ axis after an induction period, respectively, were found. During a chain-branching explosion, an induction period is necessary for accumulation of a critical concentration of

\footnotetext{
a "llie Murgulescu Institute of Physical Chemistry", Romanian Academy 202 Splaiul Independentei, RO 060021, Bucharest, Romania

${ }^{\mathrm{b}}$ University of Bucharest, Department of Physical Chemistry, 4-12 Regina Elisabeta Blvd. RO 030018, Bucharest, Romania

*Corresponding author: doan@gw-chimie.math.unibuc.ro
} 
active species. When such a system is suddenly brought into a critical state, able to react in an explosive regime, a self-ignition delay time is necessary. The ignition of the explosive regime occurs either as self-ignition, when the whole system reacts simultaneously, or as a forced ignition, starting from a small region where the ignition energy is delivered and propagates through the whole system. The self-ignition is a frequently encountered process with many applications. Consequently, many experimental techniques were dedicated and extensively used. Among these, rapid compression machines (RCM) [2-5], shock tubes (ST) [6-10] or both [11-15] are the most widespread. A qualitative description of the self-ignition delay is given in Figure 1 as a plot pressure $P$ or radiation intensity $R I$ in time:

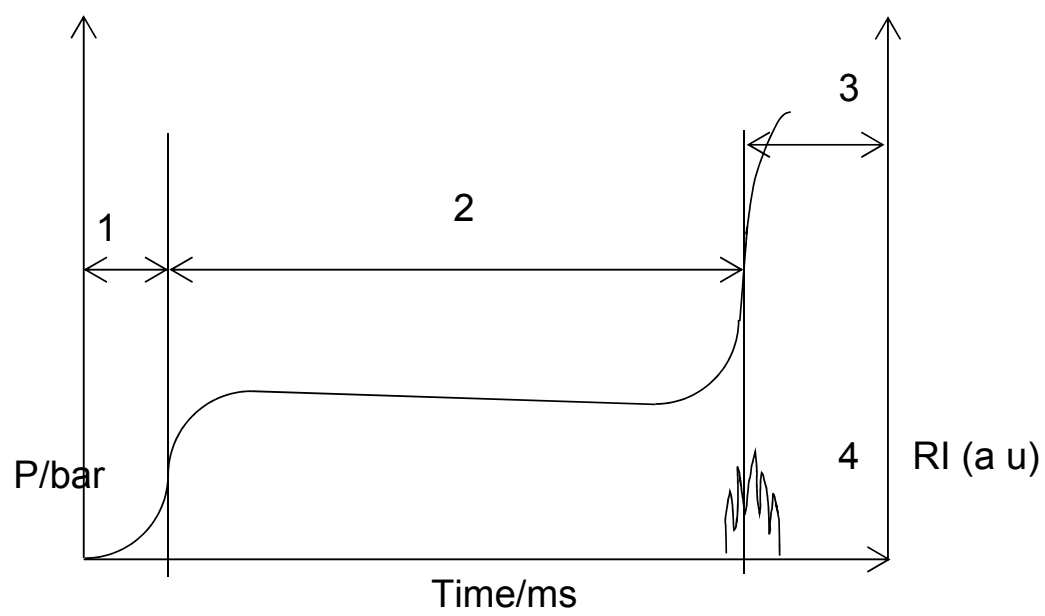

Figure 1. 1-Preignition period; 2-Ignition delay; 3-explosion; 4-Emitted radiation intensity in arbitrary units

The forced ignition, particularly spark ignition, sometimes supplemented with plasma or laser [15-20], was frequently studied using constant volume combustion bombs (CVB). The method presented in this paper relies on the analysis of the radiation intensity variation during the early stages of spark ignition in a CVB.

Due to the numerous applications of delay time in optimization of internal combustion operation, diminution of engine knocking, control of pollutant emission or validation of detailed kinetic models, the literature on these subjects is extremely rich and therefore only selected references were given. 


\section{RESULTS AND DISCUSSION}

The present paper originates in our previous work regarding the laminar flame propagation in flammable gaseous mixtures using the pressure history and intensity of emitted radiation in closed vessels. It relies on the detailed analysis of the early stages of flame propagation. The use of the third power law of pressure increase during these stages, $\Delta P$, combined with an improved statistical analysis of experimental data, resulted in a new method to evaluate the normal burning velocity and suggested the existence of an ignition delay time, $\tau$, defined as a time interval between the ignition energy deposition and the beginning of steady flame propagation [21-27]:

$$
\Delta P=\delta+k_{2}^{*}(t-\tau)
$$

where $\delta$ is the base line correction and $t$ is the time.

The method was validated either by comparing the resulted parameters with those reported in literature [21-28], or by analysing also the time evolution of emitted radiation within the same time interval [29].

This analysis relies on the deconvolution of the composite recorded curve of radiant intensity in time. It is composed of the emitted radiation due to spark emission and to flame emission. The first one is given in Figure 2.

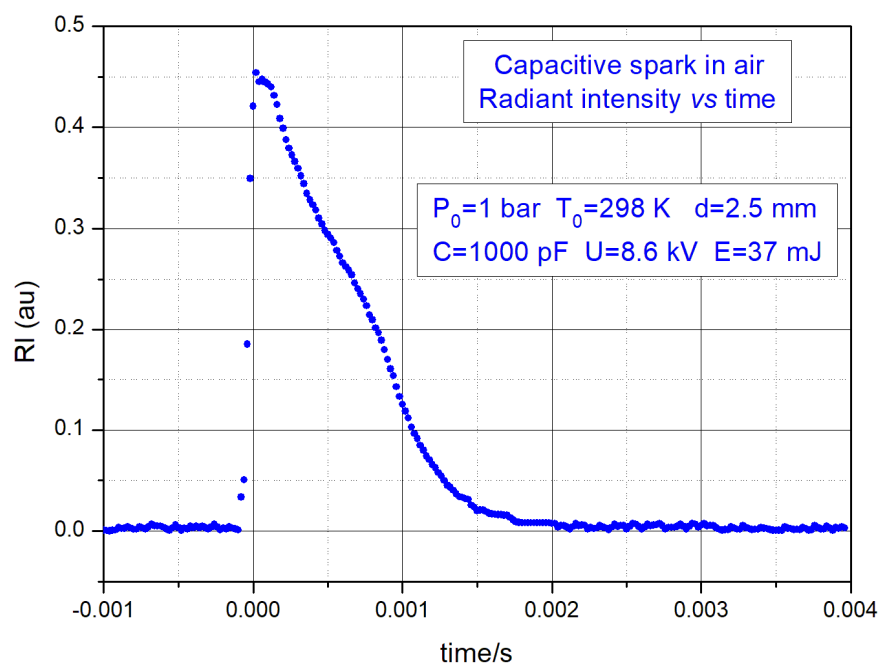

Figure 2. Radiant intensity - time due to spark emission (RI in arbitrary units) for spark gap length $d=2.5 \mathrm{~mm}$ and ignition energy $E=37 \mathrm{~mJ}$ 
Even if capacitive sparks with discharging time of $\sim 1 \mu$-second, or inductive sparks with discharging time of $\sim 1 \mathrm{~m}$-second were used, the general pattern and characteristics of the discharging emission are similar.

The composite curves, with both spark and flame emission, allow the measurement of the delay times, $\tau_{1}, \tau_{2}$, and $\tau_{3}$, defined in Figure 3.

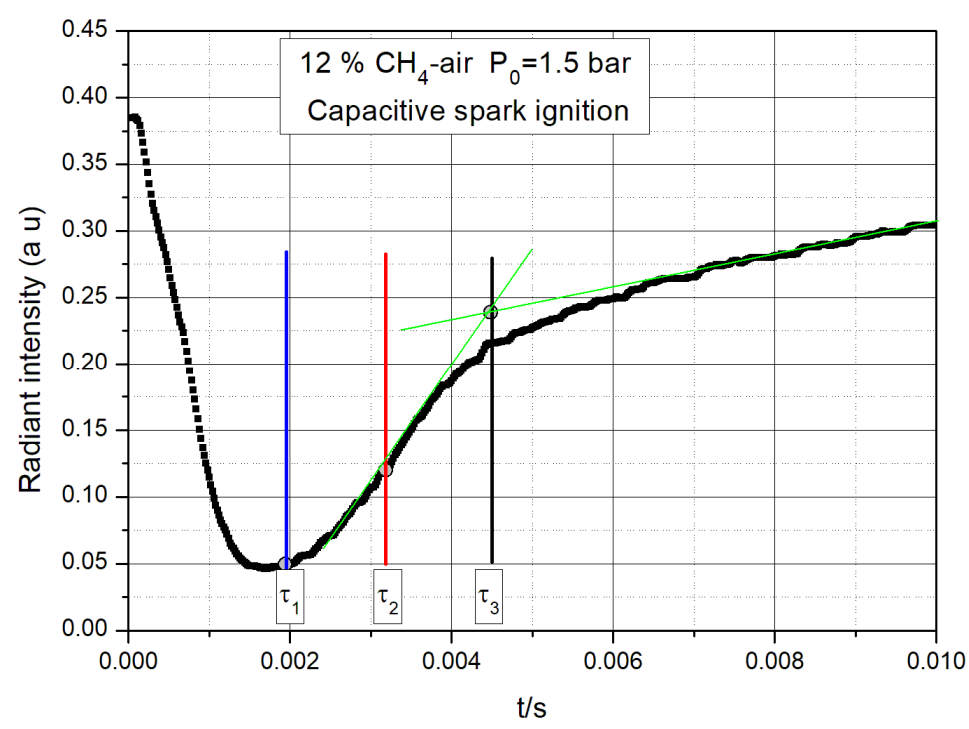

Figure 3. Experimental composite curve RI - time

There are three representative points on this curve: the first one, $\tau_{1}$, at the end of spark emission and beginning of flame emission, the second one, $\tau_{2}$, at the first inflection point of the ascending curve and the third one, $\tau_{3}$.as seen in figure.

These are dependent on the operational conditions and initial mixture composition and can be used to describe the characteristics of the ignition process. Among the most relevant operational parameters are the spark characteristics and the initial mixture pressure and temperature. The mixture composition allows also to take into account the effect of different additives, frequently used in practical applications. As will be seen, the present experimental approach allows the measurements only at normal temperature. However, if mixtures with different fuel/air ratios or explosive mixtures with inert additives are investigated, some temperature dependent properties can be investigated and compared with the data obtained from variation of the same properties by changing the initial mixture temperature. 


\section{Spark characteristics effects on ignition delay times}

The different ignition delay times can be significantly influenced by spark characteristics. To ensure similar conditions for spark discharge when pressure or composition are changed, an analysis of several operational factors is necessary. For capacitive sparks, these effects are illustrated in Figures 4 and 5 .

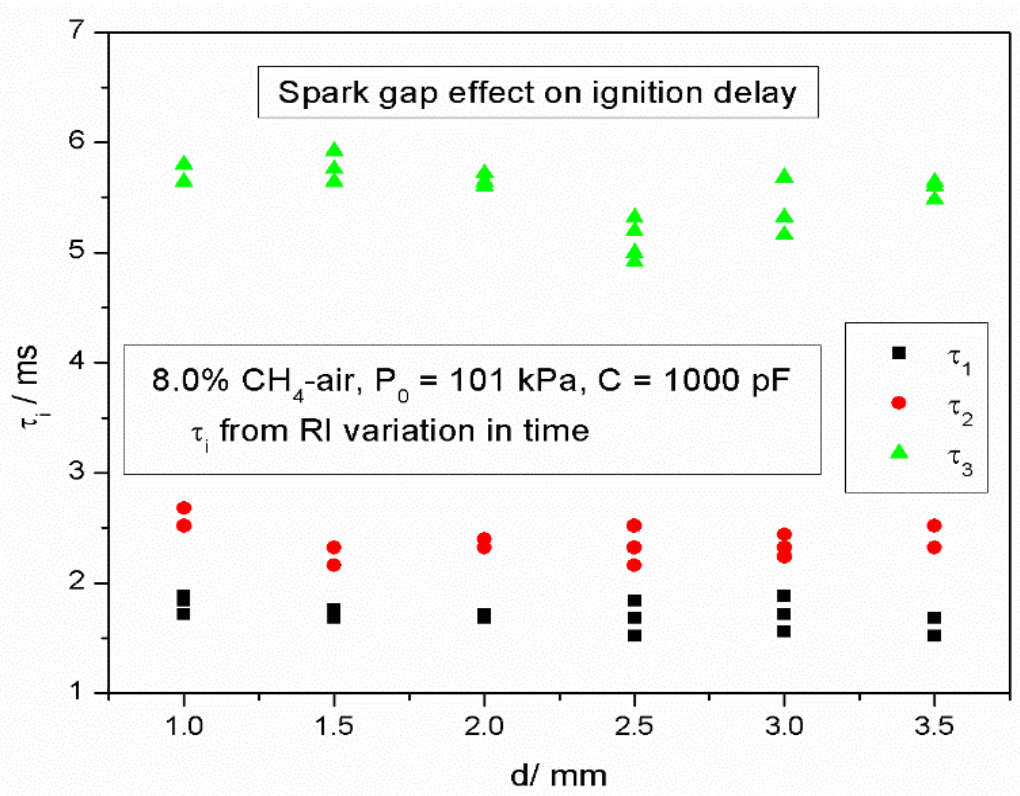

Figure 4. The effect of spark gap length $(d)$ on the ignition delay for capacitive sparks with $C=1000 \mathrm{pF}$

It can be observed that only $\tau_{1}$ exhibits the best stability within a wide interval of spark gap. The observed differences originate, presumably, from the different stages of the flame development. It can be concluded that $\tau_{1}$, when the radiant emission from the spark becomes nonsignificant and that from the minimal flame formation starts, is the best choice to be used when other operational parameters are varied. A similar trend was also observed for inductive-capacitive sparks as a function of the spark gap length. 


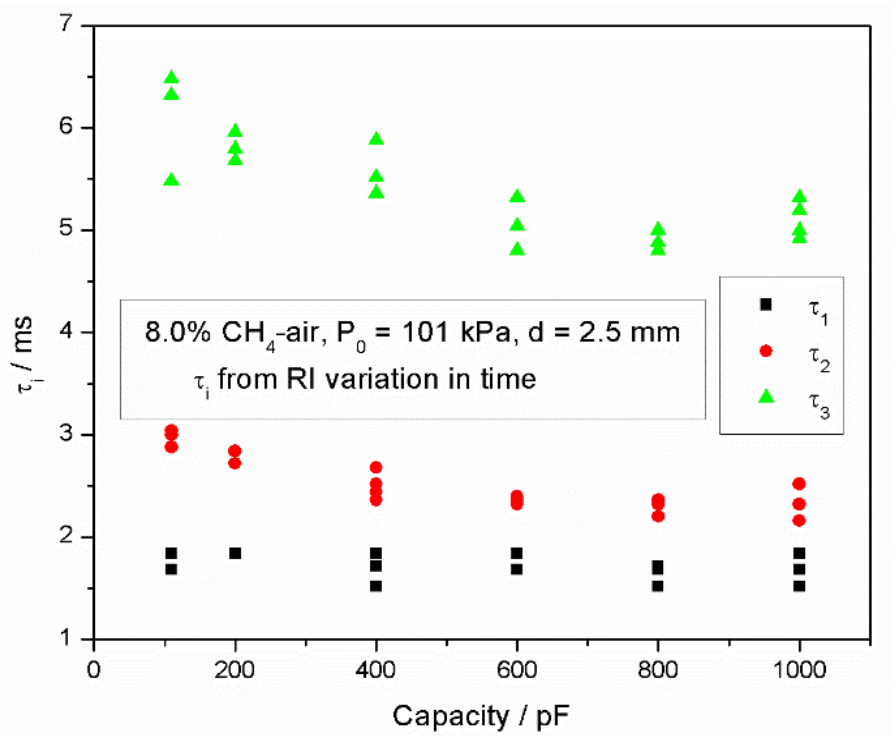

Figure 5. Effect of condenser capacity on the ignition delay for a spark gap length $\mathrm{d}=2.5 \mathrm{~mm}$

Again, only $\tau_{1}$ has the best stability within a large interval of capacity.

\section{Effect of initial pressure and temperature on the delay time}

The dependence of the ignition delay on the initial pressure and temperature of the flammable mixtures was thoroughly studied in different experimental configurations for both self-ignition and spark ignition. The most frequently, the analytical form of this dependence is of Arrhenius type: exponential with respect to temperature and product of powers with respect to other parameters [13].

$$
\tau=a_{0} \cdot \Pi P_{j}^{n_{j}} \cdot P_{0}^{b} \cdot \exp \left(E_{a} / R T\right)
$$

where $a_{0}, n_{j}$, and $b$ are empirical parameters, $P_{j}$ or $P_{0}$ is the partial or total pressure, respectively, $T$ is the temperature $(\mathrm{K})$ and $R=8.314 \mathrm{~J} \mathrm{~mol}^{-1} \mathrm{~K}^{-1}$ is the universal gas constant [30,31]. According to Equation (1), the baric coefficient $b$ has the significance of an overall reaction order.

For systems with constant composition and temperature, Equation (1) takes a simpler form:

$$
\tau=a_{0} \cdot \Pi P_{j}^{n_{j}} \cdot P_{0}^{b}
$$


or:

$$
\tau=a_{1} \cdot P_{0}^{b}
$$

where $a_{1}$ includes the mixture composition.

\section{Effect of initial mixture composition on the delay time}

Addition of different inert gases (like $\mathrm{Ar}, \mathrm{N}_{2}, \mathrm{CO}_{2}, \mathrm{H}_{2} \mathrm{O}$ or exhaust products) allows to modulate the mixture properties, including also the delay time. [32, 33] An illustrative example is given in Figure 6.

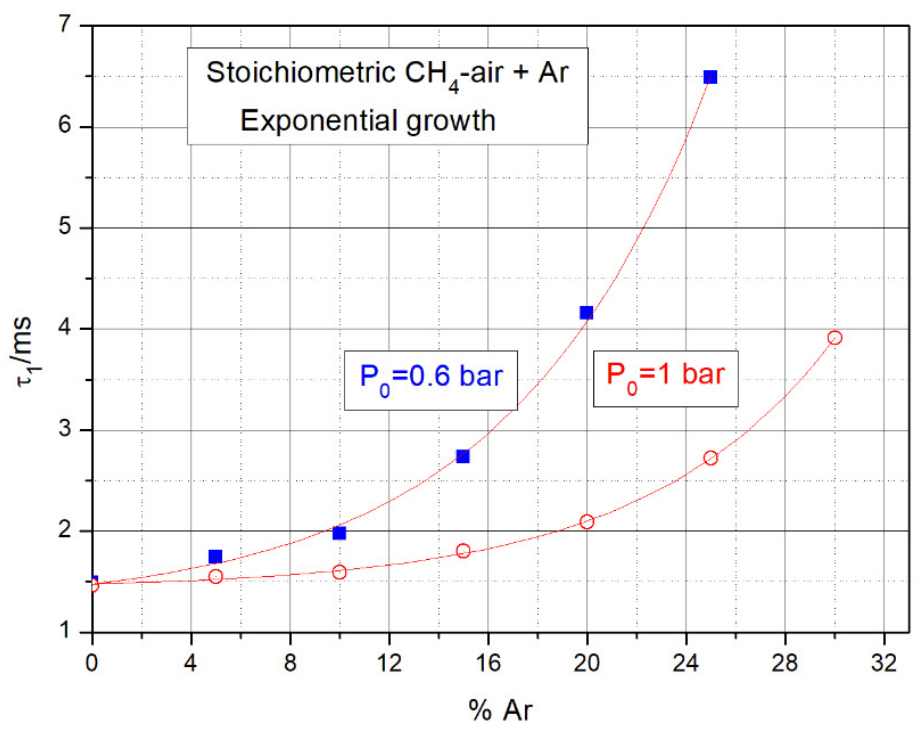

Figure 6. Effect of inert addition on the ignition delay, $\tau_{1}$

Another possibility to change the mixture properties and implicitly both the ignition delay $\tau_{1}$ and baric coefficient $b$ is to use different fuel/air ratios as given in Figure 7 for different methane-air mixtures.

Sometimes, in many practical conditions, the mixture composition can be changed using both different fuel/air ratios and inert gases addition, keeping the initial temperature constant or changing it. In these cases, the minimal flame temperature, characteristic for the critical ignition properties including the ignition delay, can be obtained only by using numerical calculations. The adiabatic flame temperatures can be calculated with ECHIMAD, the OD COSILAB package version 3.0.3 and the kinetic modelling with CHEMKIN or 1D COSILAB 
package developed by Rogg and Peters [34-39]. Due to an increased interest in this field, numerous other numerical calculations can be found in the pertinent literature [34-40].

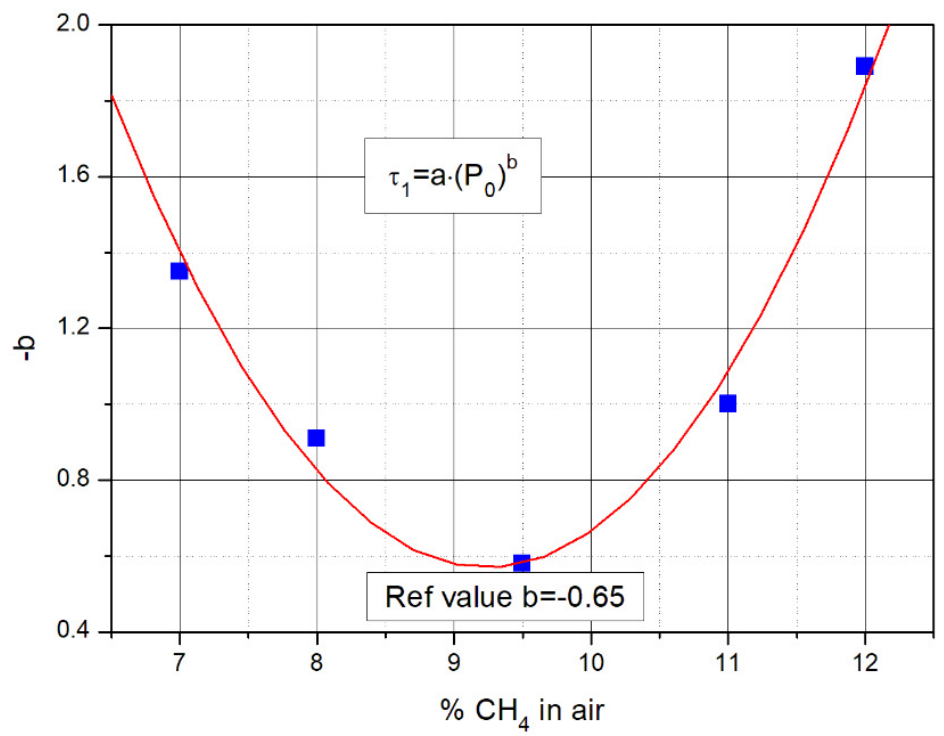

Figure 7. Variation of the baric coefficient $b$ from the law (2) with $\mathrm{CH}_{4}$ content in mixtures with air (ref. [28])

Additionally, taking into account the availability of these numerical calculations, the evaluation of temperature dependent properties becomes possible. In Table 1 the ignition delay $\tau_{1}$ can be compared to experimental or calculated maximum of pressure rise $\Delta \mathrm{P}_{\max }$ and to calculated or available from other measurements of normal burning velocity $S_{u}$.

Table 1. The efficiency of several diluting components on inerting the stoichiometric $\mathrm{CH}_{4}$-air mixtures containing $10 \%$ inert

\begin{tabular}{|c|c|c|c|}
\hline Inert & $\tau_{1 / \mathrm{ms}}$ & $\Delta \mathrm{P}_{\max } /$ bar & $\mathrm{S}_{\mathrm{u}} /(\mathrm{cm} / \mathrm{s})$ \\
\hline- & 1.46 & 5.94 & 37.40 \\
\hline $\mathrm{Ar}$ & 1.59 & 5.60 & 31.08 \\
\hline $\mathrm{N}_{2}$ & 1.79 & 5.36 & 28.35 \\
\hline $\mathrm{CO}_{2}$ & 2.45 & 4.68 & 19.14 \\
\hline
\end{tabular}

Dilution with an inerting component results in a decrease of the ignition delay and of minimal flame temperature. A corresponding activation energy can be evaluated and compared with other reference values [40]. 


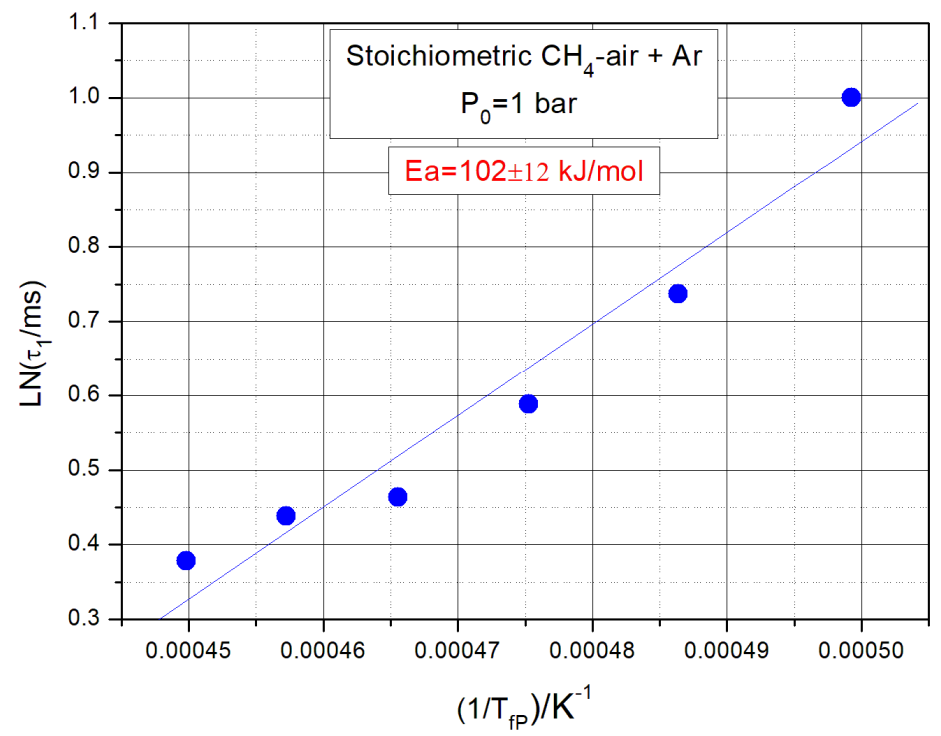

Figure 8. Variation of the ignition delay with flame temperature $T_{\mathrm{fP}}$ (calculated here at constant pressure)

To underline the significance of $\tau_{1}$, its relationships with other properties were examined. Some results are given in Figures 9 and 10:

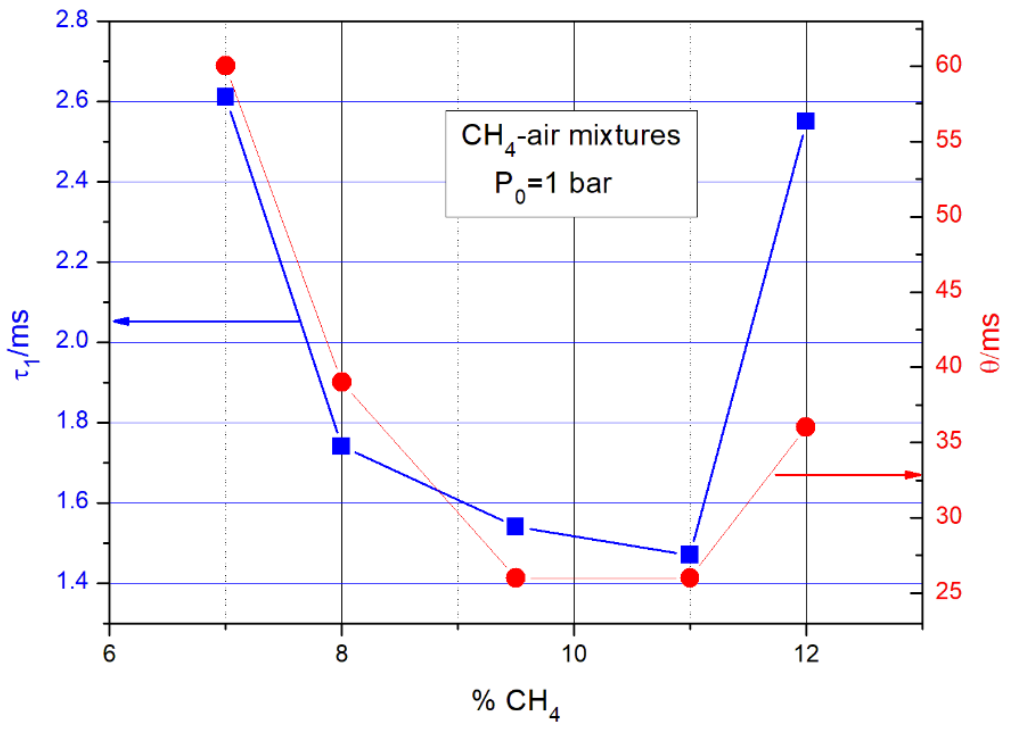

Figure 9. Comparison between the ignition delay $\tau_{1}$ and the time $\theta$ necessary to reach the maximum of the pressure rise $\Delta P_{\max }$ 


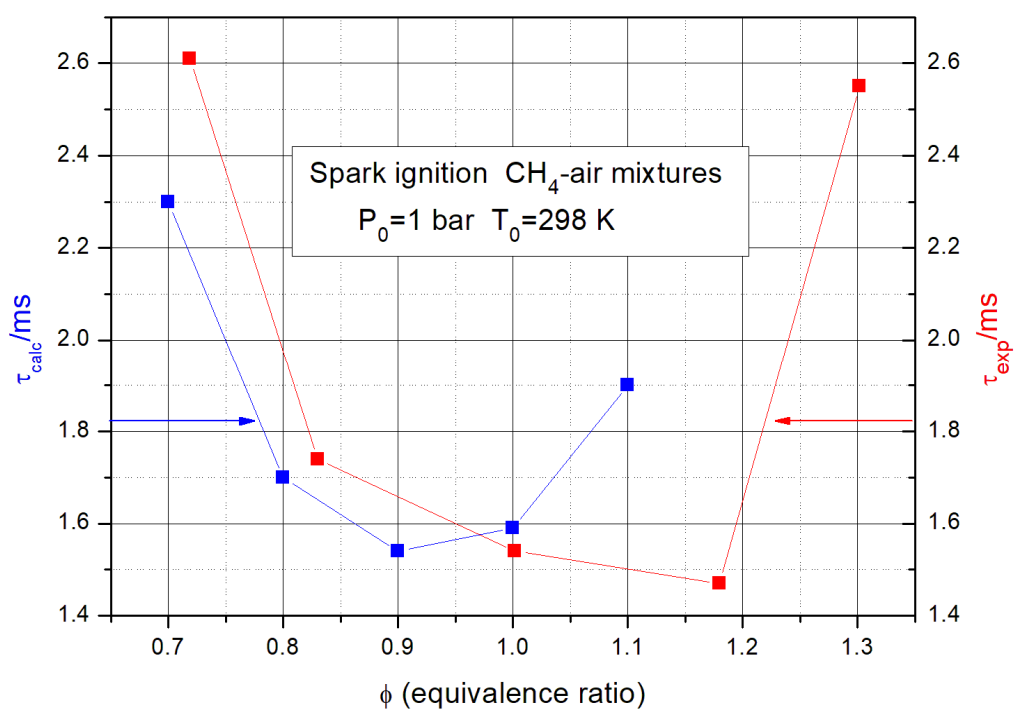

Figure 10. Comparison between experimental and calculated ignition delay.

The calculated ignition delays were obtained by using numerical calculations [34-39].

The adiabatic maximum rate of pressure rise, $\Delta \mathrm{P}_{\max } / \mathrm{bar}$, either calculated or experimental [41], measured explosion violence $(\mathrm{dP} / \mathrm{dt})_{\max } /\left(\mathrm{bar} \mathrm{s}^{-1}\right)$, calculated volumetric rate of heat release, $R_{\max } /\left(\mathrm{J} \mathrm{s}^{-1} \mathrm{~m}^{-3}\right)$ are also properties related to the measured ignition delay times. Some of these correlations will be analysed in a future paper where the effects of other operational parameters will be taken into consideration. The interest for new alternative fuels like methanol and ethanol [42-44] suggest also another direction of research based on the method discussed here.

\section{CONCLUSIONS}

Taking into account the increasing interest for the ignition delay measurement when electrical sparks are used, the development of new and simpler techniques is quite beneficial. While the pertinent literature is based preponderantly on the measurement of flame size increase using high-speed time-resolved schlieren recording, our simpler method relies on the deconvolution of the composite recorded curve of radiant intensity in time, measured with a photodiode, in a constant volume combustion bomb. It is 
composed from the emitted radiation due to spark emission superposed over of the flame emission. A procedure based on our previous paper allowed the development of this new optical method. The influence of the spark characteristics, initial mixture composition, pressure and temperature was studied and reported. Some relationships with other mixture properties were also discussed. All reported values are highly reproducible and in agreement with both experimental and calculated literature data.

\section{EXPERIMENTAL SECTION}

The experimental measurements were carried out in the Laboratory of Chemical Kinetics from the Department of Physical Chemistry, University of Bucharest, using the equipment given schematically in Figure 11.

The gaseous mixtures containing $\mathrm{CH}_{4}$, air and sometimes inert were prepared in stainless steel cylinders at 4 bar total pressure by partial pressure method using methane $99.99 \%$ purity from SIAD and used $24 \mathrm{~h}$ after mixing. The experiments were carried out in a stainless-steel cylindrical explosion cell with diameter equal to height: $\Phi=\mathrm{h}=6 \mathrm{~cm}\left(\mathrm{~V}_{0}=1.70 \cdot 10^{-4} \mathrm{~m}^{3}\right.$ and with a radius of the equivalent spherical volume $R^{*}{ }_{\text {cell }}=0.03434 \mathrm{~m}$ ). The upper lid has a transparent window made from synthetic glass allowing the observation of the radiation intensity variation with a Si PIN S 123 photodiode (Hamamatsu). The lower lid was fitted with a pressure transducer. The ignition was initiated by high voltage sparks between $1.5 \mathrm{~mm}$ diameter stainless steel electrodes with rounded tips within a spark gap of $2.5 \mathrm{~mm}$. The high voltage sparks were either capacitive or inductive. The capacitive sparks were obtained using an adjustable vacuum condenser fed from an adjustable high voltage source (Advanced Energy) interrupted at the end of discharge by an UltraVolt Opto Coupler OC250 (Voltage Multiplier INC.).

The ignition energy was higher than the minimum ignition energy $(0.29 \mathrm{~mJ})$ ensuring a safe ignition without important induced turbulence. The inductive sparks were obtained from an automotive ignition coil having the primary winding with an inductance $L=9.5 \mathrm{mH}$, fed from a dc stabilized power supply. The pressure variation during the explosion process was monitored with a Kistler piezoelectric pressure transducer type 601A coupled with a charge amplifier type 5011B and recorded using a Tektronix TDS 210 oscilloscope. 


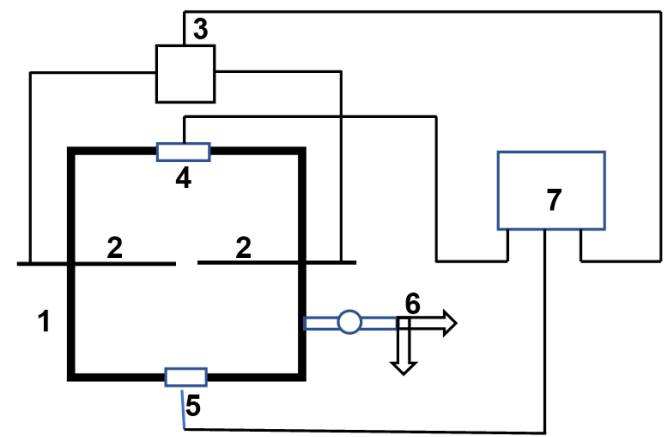

Figure 11. A simplified scheme of the experimental setup: 1. Explosion cell; 2. Spark electrodes; 3. Adjustable high voltage generator; 4. Photodiode; 5. Piezoelectric pressure transducer and charge amplifier. 6. Connections to vacuum and mixing systems; 7 . Oscilloscope connected to spark generator (3), photodiode (4) and pressure transducer (5)

\section{ACKNOWLEDGEMENTS}

The authors acknowledge the financial support of CNCSIS during the whole period.

\section{REFERENCES}

1. J. Warnatz, U. Maas, R. W. Dibble, "Combustion" $2^{\text {nd }}$ Edition, Springer, 1999, pg.144.

2. X. Nan, W. Yingtao, T. Chenglong, Z. Peng, H. Xin, W. Zhi, H. Zuohua, Proceedings of the Combustion Institute, 2017, 36, 323.

3. H. Liu, H. Zhang, Z. Shi, H. Lu, G. Zhao, B. Yao, Energies, 2014, 7, 6083.

4. S. Gersen, N. B. Anikin, A. V Mokhov, H. B. Levinsky, International Journal of Hydrogen Energy, 2008, 33, 1957.

5. P. Park, J. C. Keck, SAE Transactions, 1990, 99, 11.

6. B. Koroglu, O.M. Pryor, J. Lopez, L. Nash, S. S. Vasu, Combustion and Flame, 2016, 164, 152.

7. C. Zhang a, J. He, Y. Li, X. Li, P. Li, Fuel, 2015, 154, 346.

8. S. Li, A. Campos, D. F. Davidson, R. K. Hanson, Fuel, 2014, 118, 398.

9. Y. Zhang, Z. Huang, L. Wei, J. Zhang, C. K. Law, Combustion and Flame, 2012, $159,918$.

10. S. Saxena, M.S.P. Kahandawala, S. S. Sidhu, Combustion and Flame, 2011, $158,1019$.

11. J. Bugler, B. Marks, O. Mathieu, R. Archuleta, A. Camou, C. Grégoire, K. A. Heufer, E. L. Petersen, H. J. Curran, Combustion and Flame, 2016, 163, 138. 
12. P. Sabia, M. de Joannon, G. Sorrentino, P. Giudicianni, R. Ragucci, Chemical Engineering Journal, 2015, 277, 324.

13. U. Burke, K. P. Somers, P. O'Toole, C. M. Zinner, N. Marquet, G. Bourque, E L. Petersen, W. K. Metcalfe, Z. Serinyel, H. J. Curran, Combustion and Flame, 2015, 162, 315.

14. M. Werler, L.R. Cancino, R. Schiessl, U. Maas, C. Schulz, M. Fikri, Proceedings of the Combustion Institute, 2015, 35, 259.

15. Z. Hu, X. Zhang, International Journal of Hydrogen Energy, 2019, 44, 487.

16. L-Q. Wang, H-H. Ma, Z.-W. Shen, International Journal of Hydrogen Energy, 2019, 44, 6271.

17. L. Zhang, H. Ma, Z. Shen, L. Wang, R. Liu, J. Pan Experimental Thermal and Fluid Science, 2019, 102, 52.

18. C. Xu, A. Zhong, C. Wang, C. Jiang, X. Li, K. Zhou, Y. Huang, Biofuels Engineering, 2017, 2, 63.

19. E. Hu, X. Li, X. Meng, Y. Chen, Y. Cheng, Y. Xie, Z. Huang, Fuel, 2015, 158, 1.

20. D. K. Srivastava, M. Weinrotter, K. Iskra, A. K. Agarwal, E. Wintner, International T. Le Cong, P. Dagaut Journal of Hydrogen Energy, 2009, 34, 2475.

21. D. Razus, D. Oancea, N. I. Ionescu, Revue Roumaine de Chimie, 2000, 45, 319.

22. D. Razus, D. Oancea, C. Movileanu, Journal of Loss Prevention in the Process Industries 2006, 19, 334.

23. V. Brinzea, M. Mitu, D. Razus, D. Oancea, Revue Roumaine de Chimie, 2010, $55,55$.

24. V. Brinzea, M. Mitu, C. Movileanu, D. Razus, D. Oancea, Revista de Chimie, 2011, 62, 201.

25. C. Movileanu, D. Razus, D. Oancea, Energy \& Fuels, 2011, 25, 2444.

26. D. Razus, V. Brinzea, M. Mitu, Energy \& Fuels, 2012, 26, 901.

27. M. Mitu, D. Razus, V. Giurcan, D. Oancea, Fuel, 2015, 147, 27.

28. J. Han, H. Yamashita, N. Hayashi, Combustion and Flame, 2010, 157, 1414.

29. M. Prodan, M. Mitu, D. Razus, D. Oancea, Revue Roumaine de Chimie, 2016, 61, 299.

30. Y. Cheng, E. Hu, F. Deng, F. Yang, Y. Zhang, C. Tang, Z. Huang, Fuel, 2016, 172, 263.

31. F. S. Shariatmadar, Sh. Ghanbari Pakdehi, M. A. Zarei, Iranian Journal of Chemical Engineering, 2016, 13, 84.

32. W. Zeng,H. Ma,Y. Liang, E. Hu, Journal of Advanced Research, 2015, 6, 189.

33. T. Le Cong, P. Dagaut, Proceedings of the Combustion Institute, 2009, 32, 427.

34. D. Razus, M. Mitu, V. Giurcan, C. Movileanu, D. Oancea, Process Safety and Environmental Protection, 2018, 114, 240.

35 M. Mitu, V. Giurcan, D. Razus, D. Oancea, Revista de Chimie 2018, 69, 196.

36. M. Mitu, V. Giurcan, D. Razus, D. Oancea, Journal of Hazardous Materials, 2017, 321, 440.

37. C. Movileanu, D. Razus, A. Musuc, D. Oancea, Fuel, 2017, 193, 401.

38. C. Movileanu, D. Razus, D. Oancea, Fuel, 2013, 111, 194.

39. E. L. Petersen, M. Röhrig, D. F. Davidson, R. K. Hanson, C. T. Bowman, Symposium (International) on Combustion, 1996, 26, 799.

40. A. Burcat, K. Scheller, A. Lifshitz, Combustion and Flame, 1971, 16, 29. 
MARIA MITU, DOMNINA RAZUS, DUMITRU OANCEA

41. D. Oancea, V. Gosa, N. I. Ionescu, D. Popescu, Revue Roumaine de Chimie, 1985, 30, 767.

42. M. Mitu, E. Brandes, Fuel, 2015, 158, 217.

43. M. Mitu, E. Brandes, Fuel, 2017, 203, 460.

44. M. Mitu, E. Brandes, W. Hirsch, Process Safety and Environmental Protection, 2018, $117,190$. 